\title{
Influence of ECAP-Back Pressure on the Porosity Distribution
}

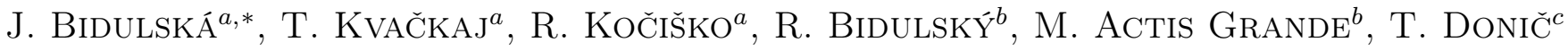 \\ AND M. MARTIKÁN ${ }^{c}$ \\ ${ }^{a}$ Technical University of Košice, Faculty of Metallurgy, Letná 9, 04200 Košice, Slovakia \\ ${ }^{b}$ Politecnico di Torino-Alessandria Campus, V. Teresa Michel 5, 15100 Alessandria, Italy \\ ${ }^{c}$ University of Žilina, Faculty of Mechanical Engineering, Univerzitná 1, 01026 Žilina, Slovakia
}

\begin{abstract}
The main aim of this paper is to show how back pressure equal channel angular pressing (ECAP-BP) influences the porosity distribution in powder metallurgy (PM) aluminium alloys. When back pressure is applied, the accumulation of damage in deformed samples decreases due to the fact that the shear strain takes place under predominantly compressive stresses. Consequently, ECAP-BP influences the porosity distribution in terms of the severe shear deformation involved. According to the obtained results, interesting applications for this new progressive method in physical and metallurgical research fields are shown.
\end{abstract}

PACS numbers: 81.05.Bx, 81.20.Ev, 81.40.-z, 81.70.Fy

\section{Introduction}

Several methods for the preparation of nanostructured materials have been developed so far. The methods can be divided into two groups: top-down and bottom-up [1].

The bottom-up methods are based on powder metallurgy (PM) techniques, on the preparation of powders and their following compaction. Despite the advances in the development of the nanopowders preparation methods, problems still remain concerning powder purity, residual porosity of compacts, grain growth at compaction, which have not been resolved yet [2].

One promising compaction technique is the back pressure equal channel angular pressing (ECAP-BP) as a severe plastic deformation (SPD) method [3-5], which enables to produce ultra fine grained (UFG) materials, especially with low ductility, such as dural [6]. When back pressure is applied, the accumulation of damage in deformed samples decreases due to the fact that the shear strain takes place under predominantly compressive stresses $[7,8]$.

Most of the properties of PM materials are strongly related to porosity. Porosity can be used as an indicative parameter to evaluate and control the processes which the components underwent [9]. The pores act as crack initiators and due to their presence distribution of stress is inhomogeneous across the cross section and leads to reduction of the effective load bearing area. Both the morphology and distribution of pores have a significant effect on the mechanical behaviour of PM materials. Two types of porosity are typically observed in sintered ma-

* corresponding author; e-mail: jana.bidulska@tuke.sk terials $[9,10]$ interconnected and isolated porosity. Interconnected porosity has a more pronounced effect on properties than isolated porosity. The effect of porosity on the mechanical properties depends on the following factors [11-13]:

- the quantity of pores (i.e., the fractional porosity);

— their interconnection;

— size;

- morphology;

- distribution.

The main aim of this paper is to show how ECAP-BP influences the porosity distribution in PM aluminium alloys.

\section{Experimental procedures}

A commercial ready-to-press aluminium based powder (ECKA Alumix 431) was used as material to be investigated. Formulation of the tested alloy is presented in Table I.

TABLE I

Chemical composition.

\begin{tabular}{c|c|c|c|c|c}
\hline \hline Material & $\begin{array}{c}\mathrm{Cu} \\
{[\text { wt.\%] }}\end{array}$ & $\begin{array}{c}\mathrm{Mg} \\
\text { [wt.\%] }\end{array}$ & $\begin{array}{c}\mathrm{Zn} \\
\text { [wt.\%] }\end{array}$ & $\begin{array}{c}\text { Wax } \\
\text { [wt.\%] }\end{array}$ & $\begin{array}{c}\mathrm{Al} \\
\text { [wt.\%] }\end{array}$ \\
\hline Alumix 431 & 1.6 & 2.5 & 5.5 & 1.0 & balance
\end{tabular}

Specimens were obtained using a $2000 \mathrm{kN}$ hydraulic press, applying two different pressures (400 and 
$600 \mathrm{MPa}$ ). Unnotched impact energy specimens $55 \times$ $10 \times 10 \mathrm{~mm}^{3}$ (ISO 5754) were prepared. Specimens were debinded in a ventilated furnace (Nabertherm) at $400{ }^{\circ} \mathrm{C}$ for $60 \mathrm{~min}$. Sintering was carried out in a vacuum furnace (TAV) at $610^{\circ} \mathrm{C}$ for $30 \mathrm{~min}$, with an applied cooling rate (post sintering) of $6^{\circ} \mathrm{C} / \mathrm{s}$.

The set-up of ECAP-BP for the produced PM materials consisted of a vertical entrance channel with a forward pressing plunger and a horizontal exit channel with a back plunger providing a constant back pressure during pressing. The die had a $90^{\circ}$ angle with sharp corners and channels of $6 \times 6 \mathrm{~mm}^{2}$ in the cross section. Specimens were then inserted in the entrance channel with graphite lubrication. A heating device was employed to heat the die to $250^{\circ} \mathrm{C}$, which was kept under control to $\pm 1^{\circ} \mathrm{C}$ through a thermocouple mounted close to the intersection of the channels. A back pressure of $100 \mathrm{MPa}$ was used. The specimens were ECAPed for 1 pass. The processing conditions are presented in Fig. 1.

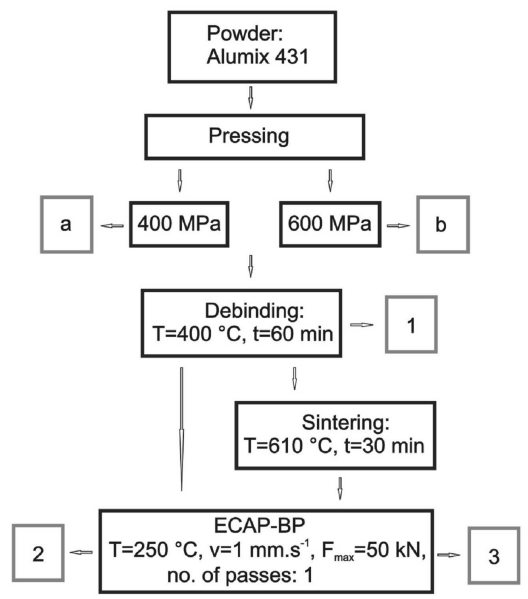

Fig. 1. Processing conditions for investigated aluminium alloy.

The metallographic specimens were impregnated with resin under vacuum in order to avoid any pore distortion during polishing. The microstructural characterization was carried out on unetched specimens using an optical microscope LEICA MPEF4 equipped with an image analyzer and SEM Jeol 7000F. Characterization was carried out at $\times 200$ on the minimum 10 different image fields; this way, pores were recorded and processed by Leica Qwin image analysis system.

The following parameters were measured individually for each pore to describe the dimensional and morphological characteristics:

- $D_{\text {circle }}$ - the diameter of the equivalent circle that has the same area as the metallographic cross-section of the pore.

- morphological characteristics $f_{\text {shape }}$ and $f_{\text {circle }}$ which reflect form of the pores.
The $f_{\text {shape }}$ represents pore elongation, while $f_{\text {circle }}$ depicts pore profile irregularity. Both parameters range between 0 and 1, being equal to unity for a circular pore. Elongation (elliptical deformation) as well as irregularity of the pore profile results in small values of $f_{\text {shape }}$ and $f_{\text {circle }}$ approaching 0 for highly elongated ones [14]. The measured values of $f_{\text {shape }}$ and $f_{\text {circle }}$ were all divided by a correction factor of 1.064 [15]. The calculations of both parameters are reported as follows:

$$
f_{\text {shape }}=\frac{D_{\min }}{D_{\max }}[-],
$$

where

- $D_{\min }[\mu \mathrm{m}]$ the parameter representing minimum of Feret diameter;

- $D_{\max }[\mu \mathrm{m}]$ the parameter representing maximum of Feret diameter;

and

$$
f_{\text {circle }}=\frac{4 \pi A}{P^{2}}[-],
$$

where

- $\mathrm{A}\left[\mu \mathrm{m}^{2}\right]$ the area of the metallographic cross-section of the pore

- $\mathrm{P}[\mu \mathrm{m}]$ the perimeter of the metallographic cross-section of the pore.

Particles size distribution, which usually represents the mass percentage retained upon each of series of standard sieves of decreasing size and the percentage passed by the sieve of finest size, was carried out by sieve analyzer according to ISO 4497.

\section{Results and discussion}

Table II shows particle size distribution of aluminium alloy 431. It can be seen from the results that the largest fraction of particles for the investigated material is in range of 63 to $100 \mu \mathrm{m}$.

TABLE II

Particle size distribution of investigated aluminium alloy Alumix 431.

\begin{tabular}{c|c|c}
\hline \hline Size fraction $[\mu \mathrm{m}]$ & Fraction $[\%]$ & St. deviation \\
\hline$>250$ & 0 & 0.1 \\
$200-250$ & 1.4 & 1.6 \\
$160-200$ & 7.3 & 0.7 \\
$100-160$ & 28.7 & 8.7 \\
$63-100$ & 48.8 & 7.3 \\
$45-63$ & 8.8 & 3.5 \\
$<45$ & 5 & 5
\end{tabular}

The unetched microstructure of the investigated material, presented in Figs. 2-4, shows difference in porosity distribution in terms of pressing pressure (Fig. 2 and 
Fig. 3). It can be seen that porosity distribution is different in the centre (Fig. 2) and the places near the corner of specimen (Fig. 4).

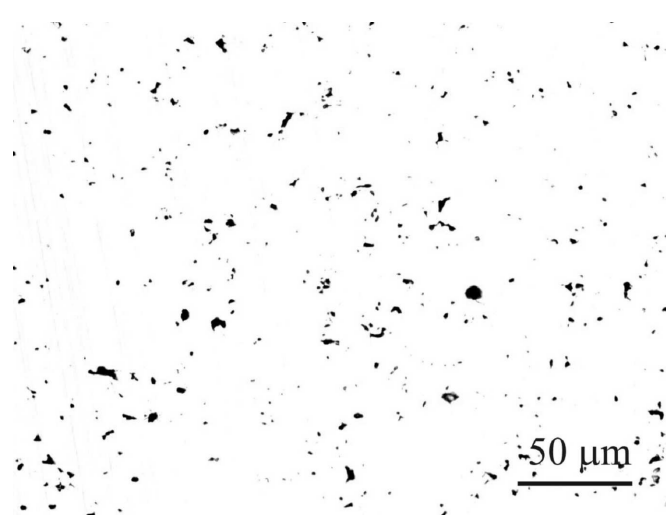

Fig. 2. The typical microstructure for $400 \mathrm{MPa}$ pressed specimens (in the centre of specimens).

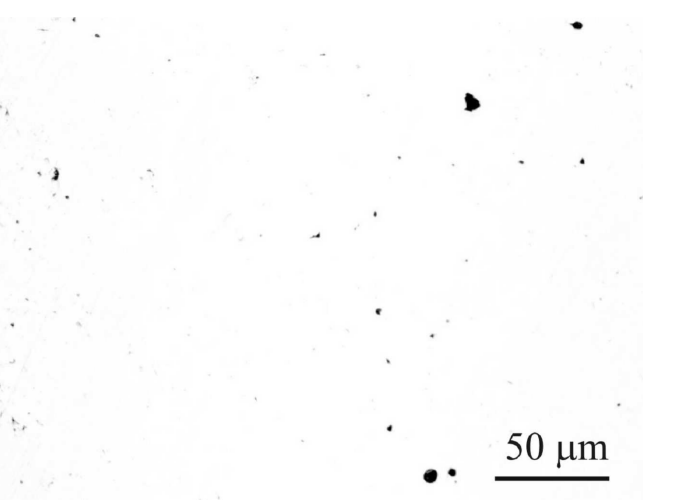

Fig. 3. The typical microstructure for $600 \mathrm{MPa}$ pressed specimens (in the centre of specimens).

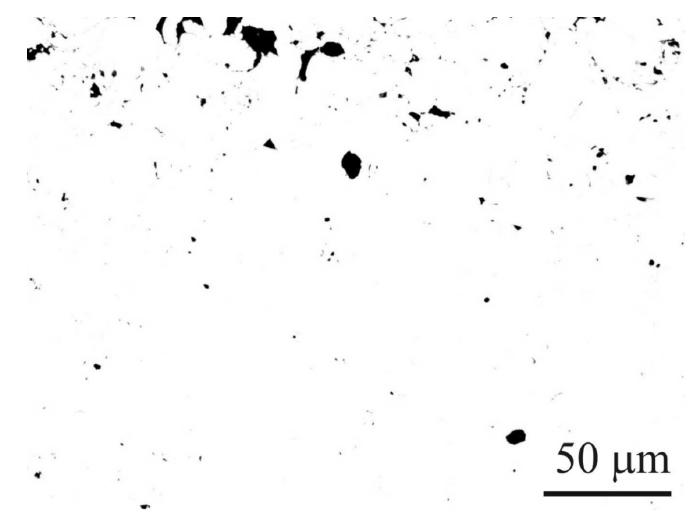

Fig. 4. Pore distribution near the corner of specimens.

Figs. 5-7 present three parameters for the investigated material processed under the three different conditions considered. As expected, sintering along with SPD tends

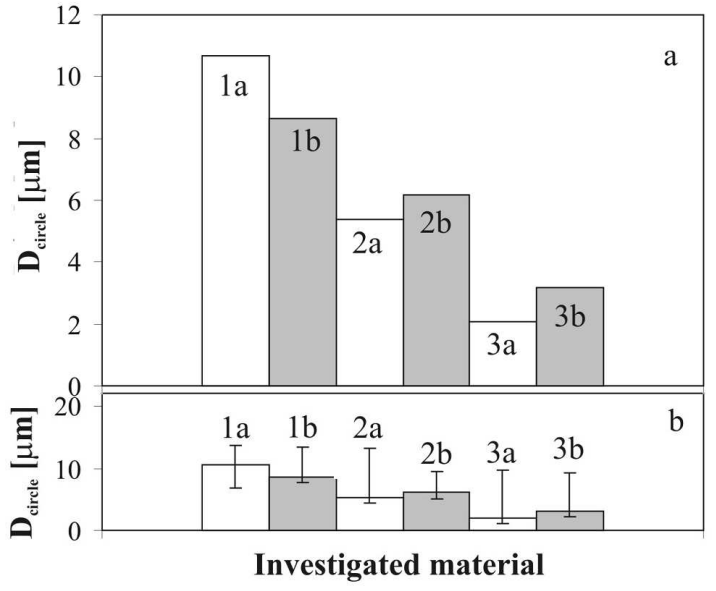

Fig. 5. (a) Mode value of $D_{\text {circle }}$ for the tested materials. (b) Minimum and maximum value of $D_{\text {circle }}$ for the tested materials.

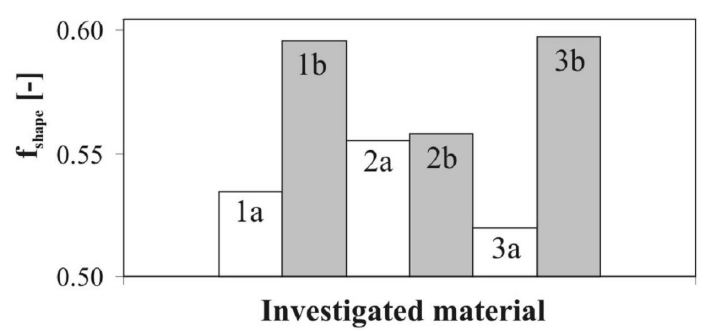

Fig. 6. $f_{\text {shape }}$ for the investigated materials when considering the whole pore population.

to shift the distributions towards lower pores size $D_{\text {circle }}$ and higher values of $f_{\text {shape }}$ and $f_{\text {circle }}$ since naturally high-temperature sintering leads to porosity reduction and improving pore morphology. Application of ECAP-BP supported next decreasing of pore size, represented by value of $D_{\text {circle }}$ (see Fig. 5). It can be noted that most of the pores diameter values are in the range from 2 to $10 \mu \mathrm{m}$ in all specimens, however rarely larger pores with the size up to $45 \mu \mathrm{m}$ were observed. It could be expected that this large amount of small pores strongly influences both $f_{\text {shape }}$ and $f_{\text {circle }}$ considering that small pores reveal preferably circular shape. The results presented in

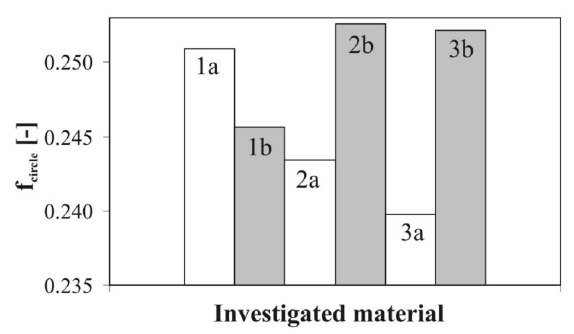

Fig. 7. $f_{\text {circle }}$ for the investigated materials when considering the whole pore population. 
Fig. 7 show a value of $f_{\text {circle }}$ is in the range from 0.23 to 0.25 . It is important to emphasize that $f_{\text {circle }}$ depicts only how circular the form of the pore is, and $f_{\text {shape }}$ include also how smooth the pore contour is, as it was shown in [16], and the evolution of pores to a smooth contour is more effective than to a circular form during sintering, so the highest value of $f_{\text {shape }}$ was registered for sintered and ECAPed specimen 3b, (see Fig. 6). Application of SPD process and sintering (as a code 3 ) causes a decrease of $D_{\text {circle }}$ to the minimum value of 2.08 for system 3a, and on the other hand, slightly increase the $f_{\text {shape }}$ to maximum value of 0.25 for system $3 \mathrm{~b}$. It is interesting that, in terms of pressing pressure, the parameter $D_{\text {circle }}$ has higher values for the initial state and the following processing causes contact areas between particles to increase and, consequently, a decrease in the effective shearing-stresses inside the particles. This condition happens with increasing densification, when the powder particles are plastically deformed and increasingly deformation strengthened. Initial state (as a code 1) tends to generate larger pores in the microstructure, because of the lower densification attained on the green parts. When back pressure is applied, the stress distribution in deformed specimens causes the powder particles to squeeze together to such an extent that the initially interconnected pores transform to small semi-isolated pores, determining a lower value of parameter $D_{\text {circle }}$, (see Fig. 7). Consequently, ECAP-BP influences the porosity distribution in terms of the severe shear deformation involving and therefore influences the pore morphology which is represented by both parameters of $f_{\text {shape }}$ and $f_{\text {circle }}$. The present results are in good agreement with previous study $[17,18]$. Authors suggested $[17,18]$ that the macroscopic shear strain experienced during compaction will promote local plastic deformation that is likely to be relatively severe in the vicinity of particle surfaces that are in contact. Such deformation will not only increase the area and proximity of contact, but also lead to local defect structures that enhance self-diffusion and promote bonding between particles across increased areas of intimate contact.

Figure 8 shows the morphologic map for the aluminium alloy specimens. The ideal curve represents the minimum limit of pore geometry, which is given by $f_{\text {circle }}$. Kubicki [19] providing a geometrical interpretation to the morphologic parameters, suggested that $f_{\text {shape }}$ and $f_{\text {circle }}$ are the parameters of the ellipse and the Eqs. (1) and (2):

$$
\begin{aligned}
& f_{\text {shape }}=\frac{D_{\min }}{D_{\max }}=\frac{a}{b}[-], \\
& f_{\text {circle }}=\frac{4 \pi A}{P^{2}}[-],
\end{aligned}
$$

can be rewritten using:

$$
A(\gamma)=\pi a b\left[\mu \mathrm{m}^{2}\right],
$$

and

$$
P(\gamma)=\pi[1.5(a b)-\sqrt{a b}][\mu \mathrm{m}],
$$

where $\mathrm{A}$ and $\mathrm{P}$ are, respectively, the area and the perime-

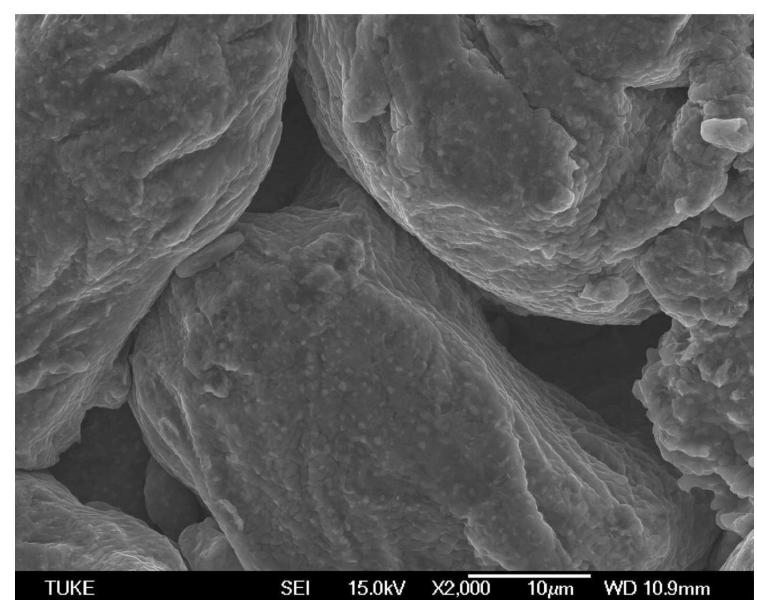

Fig. 8. Small isolated pores in the system $2 \mathrm{~b}$ with $D_{\text {circle }}$ value of $\approx 6.16 \mu \mathrm{m}$.

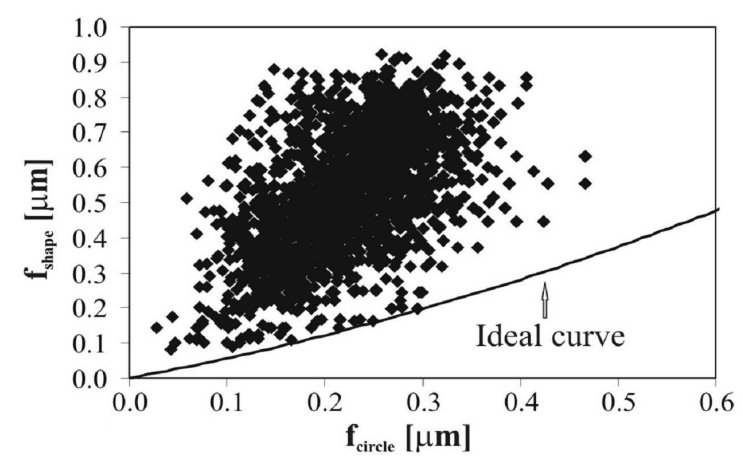

Fig. 9. Morphological map as a dependence of $f_{\text {shape }}$ vs. $f_{\text {circle. }}$.

ter of the ellipse. Then it is possible to write, that

$$
f_{\text {circle }}=4 f_{\text {shape }}\left[1.5\left(f_{\text {shape }}+1\right)-\sqrt{f_{\text {shape }}}\right]^{2}[-],
$$

Therefore, Eq. (5) constitutes a limit to the pore geometry. For a given $f_{\text {shape }}, f_{\text {circle }}$ may only be higher than the value corresponding to the equivalent smooth ellipse. The shape factor seems to be more suitable than the elongation factor to evaluate the evolution of pore morphology during ECAP-BP process. This assumption is in good agreement with the results discussed in $[13,16,20]$.

\section{Conclusion}

Coupling the experimental results obtained and the literature analysis it is possible to draw the following conclusions:

- Pore diameter for all processes materials are in the range from 1 to $45 \mu \mathrm{m}$, however most of the pores diameter values $D_{\text {circle }}$ are in the range from 2 to $10 \mu \mathrm{m}$. It could be expected that this large amount of small pores influences strongly both $f_{\text {shape }}$ and $f_{\text {circle. }}$. 
- Pore elongation, represents by morphological parameter $f_{\text {shape }}$, is in the range $0.5 \div 0.6$, and has the highest value for sintered and ECAPed specimen;

- Pore profile irregularity, represented by morphological parameter $f_{\text {circle, }}$, is in the range $0.23 \div 0.25$ and depicts evolution of pores to a smooth contour that is more effective than to a circular form during sintering, so the highest value of $f_{\text {shape }}$ was registered for sintered and ECAPed specimen as well;

- Analysis of presented parameters indicate that sintering along with SPD leads to porosity reduction and improving pore morphology, that results in improved mechanical properties;

- ECAP-BP influences the porosity distribution in terms of the severe shear deformation involved and therefore influenced the pore morphology along with pore distribution.

- The shape factor seems to be more suitable than the elongation factor to evaluate the evolution of pore morphology during ECAP-BP process.

\section{Acknowledgments}

Authors are grateful for supported of experimental works by national project VEGA 1/0035/10. R. Bidulský thanks the Politecnico di Torino and the Regione Piemonte for co-funding by the fellowship.

\section{References}

[1] Y.T. Zhu, T.C. Lowe, T.G. Langdon, Scripta Mater. 52, 51 (2004).
[2] D.G. Morris, Mater. Sci. Foundations 2, (1998).

[3] R.Z. Valiev, T.G. Langdon, Prog. Mat. Sci. 51, 881 (2006).

[4] T. Kvačkaj, M. Zemko, T. Kuskulič, R. Kočiško, M. Besterci, S.V. Dobatkin, M. Molnarová, High Temp. Mater. Process. 26, 147 (2007).

[5] J. Bidulská, T. Kvačkaj, R. Bidulský, M. Actis, Grande, High Temp. Mater. Process. 27, 203 (2008).

[6] J. Bidulská, T. Kvačkaj, R. Bidulský, M. Actis, Grande, Kovove Mater. 46, 339 (2008).

[7] V.V. Stolyarov, R. Lapovok, J. Alloys Comp. 378, 233 (2004).

[8] R. Lapovok, J. Mater. Sci. 40, 341 (2005).

[9] A. Salak, Ferrous Powder Metalurgy, Cambridge Inter. Sci. Publi. (1997).

[10] J.R. Moon, Powder Metall. Progr. 2, 63 (2002).

[11] A. Pietrowski, G. Biallas, Powder Metall. 41, 109 (1998).

[12] F.J. Esper, C.M. Sonsino, Fatigue design for PM components, Shrewsbury (UK), EPMA 1994.

[13] T. Marcu, M. Puscas, A. Signorini, G. Molinari, Straffelini, Mater. Charact. 50, (2003).

[14] Metals Handbook, 9th ed, Vol. 7, Warrendale, ASM 1984.

[15] T. Karlsson, O. Mars, Proceedings of 1998 Powder Metallurgy World Congress, Granada, 18-22 October (1998). Shrewsbury (UK), EPMA, Vol. 2, p. 662.

[16] H.C. Pavanati, A.M. Maliska, A.N. Klein, J.L.R. Muzart, Mater. Res. 10, 87 (2007).

[17] R. Lapovok, J. Mater. Sci. 40, 341 (2005).

[18] R. Lapovok, D. Tomus, B.C. Muddle, Mater. Sci. Eng. A 490, 171 (2008).

[19] B. Kubicki, Powder Metall. 38, 295 (1995).

[20] R. Bidulský, J. Bidulská, R. Kočiško, M. Actis, Grande, Acta Metallurgica Slovaca 16, 4 (2010). 